\title{
Moniz Barreto crítico de Eça
}

Carlos R eis*

* Diretor da Biblioteca Nacional de Lisboa. Professor da Universidade de Coimbra, crítico e ensaísta. 
1. A publicação do álbum Eça de Quei rós: a Escrita do Mundo, em co-edição da Biblioteca Nacional de Lisboa e de E dições Inapa, permitiu o reencontro com críticos e com textos que indiscutivelmente ocupam um lugar pioneiro no campo dos estudos queirosianos. R amalho Ortigão, J aime B atalha R eis, M achado de Assis e M oniz B arreto deram testemunho, no seu tempo, da considerável projecção, em Portugal e no B rasil, da obra do grande romancista, através de verdadeiros ensaios críticos que, de diferentes pontos de vista, estabeleceram rumos de leitura ainda hoje estimulantes ${ }^{1}$. Dois exemplos significativos do que fica dito: a análise que Machado de Assis levou a cabo, debruçando-se sobre os romances naturalistas de E ça, constitui ainda hoje um documento importante, para se entender a razão de ser de marcantes inflexões da escrita literária queirosiana²; por seu lado, a evocação a que B atalha R eis se dedicou, recordando o $E$ ça jovem e autor dos provocantes folhetins da Gazeta de Portugal, teve o mérito de acentuar o teor radicalmente inovador desses textos de iniciação, directamente conjugados com a pose e com os gestos românticos do seu autor; sintomaticamente, J osé Saramago, em depoimento inserto em Eça de Queirós: a Escrita do Mundo, lembrou a funda impres-

1 São os seguintes esses estudos: de R amalho Ortigão, "E ça de Queirós”, in Diário Ilustrado, n. 745 (22 Out.)-no 746 (23 Out.) , Lisboa, 1874; de J aime B atalha R eis, “Na primeira fase da vida literária de E ça de Queirós", introdução a Prosas Bárbaras. Porto, 1902; de Machado de Assis, “Literatura realista. O Primo Basílio romance de Eça de Queirós”, in J ornal do Comércio, no 7425 ( 13 A go.), Lisboa, 1878; de M oniz B arreto, “O Sr. E ça de Queirós. Estudo de psicologia”, in Revista Brasileira, t. XII, Rio de J aneiro, 1897.

2 Recentemente e na esteira do trabalho de Alberto Machado da Rosa (Eça, Discípulo de Machado?, 2. ed., Lisboa: Presença, s/d.) tivemos oportunidade de voltar a esta questão, no extenso estudo introdutório à edição crítica d'O Crime do Padre Amaro (L isboa: I mprensa Nacional-Casa da M oeda, 2000). 
são que Ihe causaram esses textos, apresentados por J aime B atalha R eis "na sua admirável introdução às Prosas Bárbaras." ${ }^{3}$.

2. O caso de Moniz B arreto é diferente. De todos, ele foi certamente aquele que de modo mais sistemático e informado exerceu uma actividade de crítico literário. Uma actividade que, diga-se de passagem, só não teve consequências mais amplas porque a morte prematura de Barreto, em 1896, obrigou a deixar inconclusos trabalhos como aquele de que aqui me ocuparei.

Antes disso, entretanto, vale a pena lembrar que as relações culturais entre E ça e Moniz Barreto eram relativamente antigas. Sobre diversos textos de Eça escrevera Barreto estudos críticos: sobre os folhetins da Gazeta de Portugal (antes, portanto, da publicação no volume Prosas Bárbaras, que nenhum dos dois chegou a ver), sobre a novela O Mandarim e sobre o romance Os Maias; os dois primeiros desses estudos foram refundidos e inseridos em "O Sr. Eça de Queirós. Estudo de psicologia"; todos eles republicados em colectâneas consagradas a M oniz Barreto, com destaque para as que foram organizadas por Vitorino Nemésio e Castelo Branco Chaves ${ }^{4}$.

Mas a mais flagrante prova do destaque de que gozava Moniz Barreto, no tempo de $\mathrm{E}$ ça (com reconhecimento, por este, desse destaque), encontra-se num bem evidente facto: é um longo estudo de B arreto, intitulado "A L iteratura Portuguesa contemporânea" que abre a Revista de Portugal, no seu primeiro número, publicado em 1889. O que mostra pelo menos duas coisas: que o programa da revista se cumpria em função da atenção ao contemporâneo que o ensaio de B arreto visava e que a literatura e a crítica literária deveriam ocupar, como depois se viu, um lugar importante na Revista de Portugal. Não por acaso, declarava-se no referido programa que "a Crítica entre nós nunca pôde eficazmente penetrar nos hábitos literários, nem cativar a estima geral"; a Moniz B arreto devia caber a responsabilidade de uma "função crítica, reguladora e ponderadora", exercendo desse modo "essa direcção que incessantemente afina e eleva o gosto". 5

J osé Saramago, “...mil anos passados”, in Eça de Queirós: a Escrita do Mundo. Lisboa: Biblioteca Nacional/E dições Inapa, 2000, p. 10. O volume citado inclui também o roteiro da exposição com o mesmo título, exibida na Biblioteca Nacional por ocasião do centenário da morte de Eça.

4 Respectivamente: Ensaios de Crítica. Lisboa: Bertrand, 1944; Estudos Dispersos. Lisboa: Portugália Editora, 1963. J osé R égio, em diversos números da revista Ocidente, de 1945, debruçou-se também sobre a actividade de Barreto como crítico literário (informações colhidas na Bibliografía Queirociana de Ernesto Guerra da Cal, tomo 2o A e B; Coimbra, Por Ordem da Universidade, 1976).

5 Cf. “Programa”, in E ça de Q ueirós, Textos de Imprensa IV. Lisboa: I mprensa Nacional/Casa da M oeda, 1995. p. 110-1. O Iongo ensaio de M oniz B arreto parte de considerações sobre a "psicologia nacional e estrangeira", para depois percorrer a produção literária portuguesa do século XIX, de Garrett a Teófilo Braga e Oliveira Martins, terminando com palavras muito significativas, no que respeita às conjugadas responsabilidades culturais da literatura e da crítica: “À geração que se levanta abre-se pois um vasto campo de actividade e reforma. Neste campo, largo é o terreno para a criação literária e oportuna a intervenção do espírito crítico". 
3. A extensa análise intitulada "O Sr. Eça de Queirós. E studo de psicologia" constitui um ensaio inacabado, pela primeira vez publicado na Revista Brasileira, por directa iniciativa de Domício da Gama. O que constituiu, talvez inconscientemente, uma homenagem póstuma às intensas relações culturais que Moniz $B$ arreto mantivera com o B rasil e com o público brasileiro, o que, de resto, não era raro em intelectuais portugueses do seu tempo. ${ }^{6}$

Diga-se desde já que a análise de Barreto não é (nem podia ser, pelas circunstâncias já referidas) um trabalho equilibrado nem isento de defeitos. Entre outras deficiências que, a mais de um século de distância, é possível de imediato reconhecer no que foi escrito, duas ressaltam de imediato: a tendência para parafrasear de forma quase enfadonha as obras queirosianas e o recurso a um discurso crítico um tanto empolado e por vezes perdido em divagações acessórias. J á o facto de serem relativamente parcas as considerações sobre os grandes romances de Eça - e designadamente sobre Os Maias - é compreensível, se de novo nos lembrarmos de que estamos perante um trabalho incompleto.

Apesar disso, a análise que Moniz Barreto leva a cabo encerra elementos e juízos muito interessantes, em que vale a pena surpreender a argúcia e a inteligência crítica do seu autor, tanto mais apreciáveis quanto é certo que, na época, a crítica literária não possuía os instrumentos operatórios de que hoje dispomos; do mesmo modo, a bibliografia queirosiana era escassa e, por razões óbvias, não podia ainda olhar-se a obra de Eça - uma obra que então estava em desenvolvimento, note-se - com o distanciamento de que hoje beneficiamos.

Um aspecto certamente muito interessante do processo analítico de Moniz B arreto tem que ver com uma tentativa de classificação modal (como hoje diríamos) da produção literária queirosiana ou, pelo menos, de alguns dos seus textos. "Há no Sr. Eça de Queirós um grande poeta e um romancista digno de atenção", declara-se a abrir, como se (surpreendentemente) a primeira característica fosse, de facto, a predominante e a condição de romancista devesse ser tratada como menor ou acessória. E continua Barreto:

Dos poetas ele tem a sensibilidade, e dos grandes poetas a sensibilidade extrema. É este a meu ver o facto mais importante do seu espírito e o mais saliente da sua obra. No começo mesmo da sua carreira literária, inda isento de preocupações morais e de intenções de escola, já ela aparece, intensa e patente ${ }^{7}$.

6 Na nota preambular de Castelo Branco Chaves a Estudos Dispersos estão descritas as circunstâncias da morte e publicação póstuma do estudo sobre Eça, sublinhando-se também a precariedade de um trabalho que certamente ficou longe de estar terminado.

Eça de Queirós: a Escrita do Mundo. ed. cit., p. 135. 
O que aqui fica vale sobretudo como tentativa para apreender, no plano psicológico que Barreto deseja privilegiar, qualidades que, para o crítico, se encontram aquém de concretizações de género ou das determinações ideológicas que caracterizam o E ça naturalista. Para além disso, trata-se também, como logo depois pode ler-se, de acentuar a individualidade de Eça no contexto da sua geração, por explícito confronto com características dominantes como as que são assinaladas em Oliveira M artins, em A ntero de Quental, em Teófilo B raga e também em Camilo; uma individualidade que de novo se observa na "sensibilidade pura" apontada em Eça, uma sensibilidade que desemboca nisso a que chamei a classificação modal operada pelo crítico: "A sua prosa é lírica” (p. 136).

4. Convém notar que, quando assim se exprime, M oniz B arreto está já a ocupar-se dos folhetins da Gazeta de Portugal. O que revela, na atenção conferida a esses textos de juventude para muitos certamente já esquecidos na época ${ }^{8}$, uma argúcia crítica que deve ser registada. Com efeito, hoje sabemos que esses escritos tiveram, na formação literária de $\mathrm{E}$ ça (e conforme, antes de todos, mas depois de $B$ arreto, notou $B$ atalha $R$ eis), um papel relevante, muito para além da provocação e da subversão literária que aparentavam e a que poderiam ser injustamente reduzidos.

O que M oniz B arreto vem notar é o significado e o potencial de continuidade de um E ça intrínseca eautenticamente romântico. U m E ça que, no dizer de B arreto, recusa a anteriori o que depois escreverá - asserção que, diga-se de passagem, não seria por certo subscrita por uma história literária ponderada e fundamentada. Mas lembremos as palavras do crítico:

[Eça] Refuta de antemão toda a sua obra futura pela espécie das suas predilecções literárias e artísticas, pela qualidade do seu estilo, pela intemperança da sua fantasia, pelo seu confessado desdém da observação minuciosa, da cópia fiel e da análise exacta, pela sua definição do romance e do drama, considerados como a pintura do homem entregue às fatalidades da paixão e do temperamento, às tiranias dos desejos e dos instintos, longe das influências da sociedade, das instituições e dos costumes. (p. 137).

"Toda a sua obra futura" reporta-se certamente a romances como O Crime do Padre A maro e O Primo Basíli o, obras consabidamente marcadas pela disciplina naturalista e pelo concretizado propósito de analisar as "influências da sociedade, das instituições e dos costumes". O que, estando embora em sintonia com conhecidas posições assumidas por Machado de Assis, constitui um juízo

8 Mesmo em 1888, quando Moniz B arreto publica, n'O Repórter e com o título “A estreia de um escritor", as páginas que recupera para este estudo. 
excessivamente generalizador, só compreensível pelo facto de Moniz Barreto pretender valorizar em Eça textos em que se reencontram vectores estéticos iniciados na Gazeta de Portugal, de certa forma prolongados no relato A Morte de J esus e no romance epistolar O Mistério da Estrada de Sintra. São eles que, por fim, concretizam o que designei como potencial de continuidade da produção queirosiana, representando um veio temático que B arreto sintetiza nos seguintes termos:

Não é difícil mostrar na Carmen do Mistério a sensibilidade violenta e a imaginação desenfreada que, depois de ter feito explosão nos folhetins da Gazeta de Portugal e da Revolução de Setembro, produziu as estranhas e pungentes fantasias do Mandarim e da Relíquia. (p. 138)

5. A linha de continuidade que M oniz B arreto procura estabelecer, acompanhando o desenvolvimento da obra queirosiana, procura valorizar em E ça um aspecto que o escritor não raro destacou, nele mesmo de forma discreta e noutros em termos expressivos: a dimensão propriamente artística da escrita literária, aparentemente valorizada e incrementada quando o escritor se libertava de imposições de escola.

Essa dimensão artística é a que, por exemplo, leva Eça a fazer o elogio dos valores do idealismo artístico, quando escreve o conhecido prefácio dos Azulejos do Conde de Arnoso. De uma forma ao mesmo tempo mais radical e mais sinuosa, é ainda nessa faceta que culmina a estesia e a poética do fradiquismo: em função dessa que vem a ser uma poética da perfeição inefável e inalcançável, o escritor acaba por se reduzir ao silêncio de quem, à força de almejar uma (inatingível) beleza suprema, termina por legar à posteridade não uma obra, mas a sua pura e absoluta ausência. A petece dizer: foi pena que M oniz B arreto não tivesse chegado a $\mathrm{F}$ radique $\mathrm{M}$ endes, no termo de chegada do raciocínio crítico que tenho vindo a acompanhar.

Num outro plano de análise, poderia ainda dizer-se que, ao realçar em Eça o poder evocativo da "mão do artista", M oniz B arreto não anula nem cancela a componente propriamente naturalista da produção queirosiana: nos primórdios da sua aprendizagem naturalista, quando escreve as duas primeiras versões d'O Crime do Padre Amaro, E ça distancia-se de Antero (e mesmo confronta-se com ele), por entender incompatível com o reformismo moralizante do poeta das Odes Modernas uma vocação estética que recusava contornar temas, situações ou personagens, por mais estranhas e mesmo repulsivas que fossem. E m certa medida, são essas diferenças de orientação que emergem no incidente relativamente agreste ocorrido entre Eça e Antero (com Batalha R eis de permeio), quando da publica- 


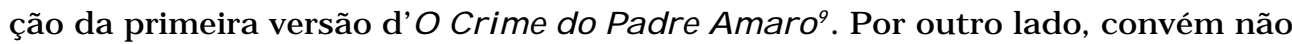
esquecer que, em certos aspectos, a poética do R ealismo e do Naturalismo podia desembocar (e nalguns casos foi isso mesmo que aconteceu) num apurado culto da descrição, cujas minudências e propósitos de rigorosa evocação do real representado confinavam com atitudes de refinamento esteticista como as que foram cultivadas pela estética parnasiana; num outro plano, a chamada "escrita de artista", defendida pelo naturalista Edmond de Goncourt, traduzia, no contexto de uma evolução de recorte finissecular, uma atitude esteticista de coloração decadendista, atitude de que Fialho de Almeida foi, em Portugal, um exemplo significativo.

6. O que fica dito afasta-se aparentemente do texto de Moniz Barreto e do esboço de leitura crítica da obra queirosiana que nele se encontra. M as só aparentemente, porque, de facto, o ensaio de B arreto funciona também como estímulo a uma reflexão actual sobre uma produção literária que, como é o caso da de Eça de Queirós, comporta feições não raro contraditórias, assim encerrando, afinal, um inegável potencial de fascínio e de renovação crítica.

No fundo, o estudo inacabado de Moniz Barreto revela, entre outros aspectos (e também a par de limitações que agora não procuro apontar), um E ça dominado por duas fundamentais polaridades, instaurando "duas concepções diferentes da vida" (p. 141) , na origem de quase opostos rumos de análise que têm caracterizado a abordagem da obra queirosiana, de há cerca de um século para cá, em Portugal e também no Brasil. U ma dessas polaridades é a que decorre da sensibilidade "às emoções pagãs, ao culto da força imoral e da beleza plástica, ao livre jogo dos instintos animais e da actividade individual, à poesia do riso e do gozo, às alegrias do combate e da vitória" (p. 141). Tudo o que Moniz Barreto sintetiza, reportando-se sempre a $\mathrm{E}$ ça, nestes termos expressivos:

Há nele um poeta pagão, ébrio de entusiasmo pela magnificência da M atéria, pelo encanto da B eleza, pelo prestígio da força, pelas seduções do luxo. (p. 141)

E ste E ça é o d'O Mandarim, ou seja, o da “história fantástica de um amanuense do M inistério do R eino" ( p. 141), história sobre a qual B arreto se alonga em paráfrases, mais do que em indagações de propensão hermenêutica. O mesmo acontece com A Relíquia, romance em que se observa a dominância das caricaturas (Teodorico Raposo e D. Patrocínio, por exemplo), como "produtos da imaginação lírica" e não do "espírito analítico" (p. 149); uma "imaginação lírica” que em gran-

9 A revisão crítica do episódio aqui referido foi feita na introdução à edição crítica d'O Crime do Padre Amaro (edição de Carlos R eis e Maria do Rosário Cunha. Lisboa: I mprensa Nacional/Casa da M oeda, 2000. p. 19 ss.). 
de parte motiva o longo capítulo III, sobre o qual M oniz B arreto se debruça com demora.

Por fim, surge o outro Eça, aquele que, insistindo no culto das "emoções intensas", cultiva "a aptidão para as fazer reflectir no espelho da consciência e parta as desfiar sob o escalpelo da análise" (p. 150). É agora o romancista de costumes e de crítica social que está em causa, romancista cuja produção gira em torno de três obras cruciais: O Crime do Padre A maro, O Primo Basílio e Os Maias. "Por estes três livros", observa M oniz B arreto, "E ça de Queirós renovou e até certo ponto fundou o romance português", superando um relativamente escasso legado nacional, dominado por Herculano, Camilo e J úlio Dinis.

Seja como for: ou porque não chegou a ter tempo para, de facto, se consagrar aos três romances ou porque, tanto quanto parece, eles não o atraíam tanto como os textos em que se evidenciava o "poeta pagão", M oniz B arreto não chegou a fazerIhes a justiça que a subsequente crítica queirosiana havia de confirmar. O que não impede que, pelo menos num aspecto, Barreto tenha aberto um veio de análise extremamente fecundo: refiro-me à atenção que, apesar de tudo, acabou por conferir à vida psicológica das personagens, sobretudo as femininas e, em particular, a A mélia e a Luísa, aos seus traumas e à sua imaginação um tanto doentia.

Assim se explana a intuição de que, por esse caminho, o romance queirosiano esboçava uma verdadeira revolução romanesca, que outros haviam de prosseguir. E é também porque essa intuição revela uma argúcia crítica notável que é legítimo pensar que o contributo de Moniz Barreto para a fundação dos estudos queirosianos teria sido muito mais expressivo, se a vida lhe não tivesse faltado, privando-o de conhecer o último Eça: o de obras como A Correspondência de Fradique Mendes, A Ilustre Casa de Ramires e A Cidade e as Serras, marcos de uma modernidade literária que em Portugal estava a começar. 